\title{
Polymer Electrolyte Membrane Electrolyzer and Fuel Cell
} System Characterization for Power System Frequency Control*

This paper was downloaded from TechRxiv (https://www.techrxiv.org).

LICENSE

CC BY-NC-SA 4.0

SUBMISSION DATE / POSTED DATE

$19-01-2022$ / 24-01-2022

\section{CITATION}

Peter, Christian; Vrettos, Evangelos; Büchi, Felix N. (2022): Polymer Electrolyte Membrane Electrolyzer and Fuel Cell System Characterization for Power System Frequency Control*. TechRxiv. Preprint. https://doi.org/10.36227/techrxiv.18667595.v1

$\mathrm{DOI}$ 


\title{
Polymer Electrolyte Membrane Electrolyzer and Fuel Cell System Characterization for Power System Frequency Control ${ }^{\star}$
}

\author{
Christian Peter ${ }^{a, *}$, Evangelos Vrettos ${ }^{\mathrm{b}}$, Felix N. Büchi ${ }^{\mathrm{a}}$ \\ ${ }^{a}$ Electrochemistry Laboratory, Paul Scherrer Institut, Forschungsstrasse 111, Villigen PSI, 5232, Aargau, Switzerland \\ ${ }^{b}$ Swissgrid AG, Bleichemattstrasse 31, Aarau, 5001, Aargau, Switzerland
}

H I G H L I G H T S

- Successful frequency control test results on real, sub-MW systems are presented.

- The ramping capabilities of the Power-to-Gas and Gas-to-Power systems are identified.

- The efficiencies of the polymer electrolyte membrane based systems are determined.

- The future efficiencies, while utilizing oxygen in the process, are estimated.

- Fundamental data for assessing frequency control suitability is made available.

\begin{abstract}
A R T I C L E I N F O
A B S T R A C T

Keywords:

Control reserve

Frequency control

Hydrogen

Renewable energy

Energy storage

Efficiency

This work focuses on tests for control reserve of a novel Power-to-Gas-to-Power platform based on proton exchange membrane technologies and on pure oxygen instead of air in the re-electrification process. The technologies are intended as a further option to stabilize the power system, therefore, helping integrating renewable energy into the power system. The tests are based on the pre-qualification tests used by Swissgrid, but are not identical in order to capture the maximum dynamics by the plants. The main characteristics identified are the ramping capabilities of $\pm 8 \%$ per unit per second for the electrolyzer system and $\pm 33 \%$ per unit per second for the fuel cell system. The ramping capabilities are mainly limited by the underlying processes of polymer electrolyte membrane technologies. Additionally, the current and projected round-trip efficiencies for Power-to-Gas-to-Power of $39 \%$ in 2025 and $48 \%$ in 2040 are derived. Furthermore, during the successful tests, the usage of oxygen in the present Power-to-Gas and Gas-to-Power processes and its influence on the dynamics and the round-trip efficiency was assessed. In consequence, fundamental data on the efficiency and the dynamics of the Power-to-Gas-to-Power technologies is presented. This data can serve as basis for prospective assessments on the suitability of the technologies investigated for frequency control in power systems.
\end{abstract}

\section{Introduction}

In the course of the worldwide decarbonization strategy, as for example in the case of the European Union in its strategic long-term vision for a climate neutral economy [1], integrating variable renewable energy into the power system has and will have a severe impact on the electric grid [2]. Therefore, grid operating companies are facing challenges to operate the electric grid in a stable manner.

Besides today's existing ancillary service products, as for example primary frequency control, often covered with pumpedstorage hydropower (PSH) plants, further product categories are under development, in order to keep up with the dynamics of renewable energy inrush, be it ramping products or fast

\footnotetext{
*This research is supported by the ETH Domain via the funds for "Coordinated Research" and by Swissgrid AG.

*Corresponding author.
}

frequency response, most likely carried out by batteries [3]. Potentially, Power-to-Gas (PtG) and Gas-to-Power (GtP) using polymer electrolyte membrane (PEM) based technologies may play an important role in these new fields of ancillary service products, as well. Similar to batteries, electric energy can be stored in electrochemical bonds and be re-electrified using the energy conversion processes $\mathrm{PtG}$ and GtP.

Research and projects identifying the potential and demonstrating the operation of these energy conversion technologies in the context of control reserve, have already been conducted with batteries [4] or with electrolyzers [5]. The latter work summarizes the topics of dynamics and efficiency for electrolyzers, and reports on the pre-qualification of a PEM electrolyzer in the Thüga project. In addition, a PEM electrolyzer already provides primary frequency control reserve in Hassfurt (Germany) [6].

The characteristics of PEM electrolyzers have been studied extensively and corresponding models are reviewed in [35]. There 
are studies with PEM fuel cells discussing the aspect of supporting primary frequency in a stand-alone microgrid [7]. Furthermore, [8] indicates the potential of PEM fuel cell based technology in the application of telecommunication backup power by analyzing their economics when providing grid services.

And [9] reports on the characteristics of PEM hydrogen technologies and their potential suitability for ancillary services. Their work is based on dynamic generic models. The dynamic fuel cell stack model stems from [29]. It captures the transient behavior of fuel cells, whereas models, as shown in [30], describe the static characteristic only. The aforementioned stack models are validated against measurements. The models can be scaled up and extended with system-like characteristics using a static generator in simulation.

A fuel cell system using air as oxidant is characterized in [33], and the influence of the operating conditions on the performance is shown, as well. The modelling of a fuel cell stack combined with system components is shown in [32], resulting in a controloriented model. Next to this approach [34] presents a dynamic model of a PEM fuel cell system, consisting of first- and secondorder terms. Furthermore, the dynamic response of fuel cells is analyzed and modelled in the form of a first-order system in [31]. Ultimately, a study in [36] reports on a micro-grid containing a fuel cell and an electrolyzer, disclosing their first-order transfer functions. The fuel cell's one comes with a time-constant of four seconds, the fastest one found among the references investigated.

Even though some of the above models contain dynamic information, the maximum ramping capability of real PEM fuel cell systems in the order of several $100 \mathrm{~kW}$ cannot be derived from it, necessarily. Either the fuel cell type is different from PEM based systems or the data stems from small scale stacks in the order of a few $\mathrm{kW}$, extended with system components, which were tested in laboratory and not in real world conditions. In this work, the goal was to derive the maximum ramping capabilities of real PEM based systems. These ramping capabilities are compared with the battery ramping capability of around $200 \%$ p.u. per second [18] or with the one of pumped-storage hydropower of around $10 \%$ p.u. per second [19].

Next to the ramping capability, the energy capacity of a technology plays an important role. There are regulatory boundary conditions on the size of energy capacity to be held in storage per MW of offered power for primary control reserve, as discussed in [10]. Under this aspect, battery technology may be in danger of becoming economically unattractive, if too much energy capacity is required to be held in reserve. Such strict regulations can be an advantage for hydrogen energy storage using PEM electrolyzers and fuel cells, since the costs and required installation space for additional energy capacity does not scale as it does for batteries, considering today's energy capacity prices of at most 60000 EUR for $1 \mathrm{MWh}$ for gas storage infrastructure [11] versus approximately 775000 EUR for $1 \mathrm{MWh}$ battery storage [12].

Therefore, PEM technologies may be an attractive substitute over batteries in the control reserve market. Furthermore, hydrogen storage in combination with compressed air in the re-electrification process comes typically with a lower roundtrip efficiency than what batteries do achieve, which come with a round-trip efficiency of around $90 \%$ [17]. Stationary applications, as for example built by Hydrogenics (now Cummins, Canada) [20], have an electrical efficiency of around 50\%. It is expected, that the usage of oxygen, which enhances the electrokinetics of the oxygen reduction reaction in the fuel cell as discussed in [14], will contribute to outperform the aforementioned fuel cell process efficiency. Hence, using pure oxygen instead of air may have a substantial effect in narrowing the gap in the efficiency when comparing PtGtP to batteries.

In this work, we therefore look deeper into the characteristics and potential of hydrogen energy storage using PEM electrolyzer (EL) and fuel cell (FC). The GtP process at the Energy System Integration platform (ESI) at the Paul Scherrer Institute in Switzerland [13] is implemented to enhance the efficiency, i.e. to store and then use the oxygen produced by the electrolyzer in the re-electrification process.

The analysis is performed on the system level with demonstrator size (approximately $100 \mathrm{~kW}$ ) and the findings are extrapolated to industrial sized plants in the MW domain for future applications. The contributions of this paper are summarized as follows:

- The study identifies the ramping capabilities of real, subMW PEM electrolyzer and fuel cell demonstrator systems when using the "by-product" oxygen. The ramping capabilities are inherently connected with the systems' transfer functions and are put into relation with frequency control for the power system. The system setup and characterization when using pure oxygen in the PtGtP process, as well as the fuel cell system's ramping capability on this system level are to the best of our knowledge unprecedented.

- The key factors impeding faster dynamics and the main limitations of the operating domain are discussed.

- It determines the efficiencies of the PEM based energy conversion processes, using the recorded data of the systems operated on ESI. By aggregating these efficiencies, the PtGtP round-trip efficiency achieved with the present technology can be derived in a first step and from that, when including prospective technology improvements, the future round-trip efficiencies in 2025 and in 2040 can be estimated.

- The findings for ramping capability and efficiencies are compared to other technologies such as batteries, pumpedstorage hydropower and for the re-electrification part they are compared to the state of the art hydrogen/air fuel cell technology. The fundamental data derived, can serve as a basis for future assessments on the suitability of PEM technologies for ancillary services and can be used for modelling tasks in simulation.

- Finally, the study reports on the successful tests for primary and secondary frequency control and the integration into the local power system of PEM technology based systems. The tests follow closely the pre-qualification tests for the corresponding products applied by Swissgrid, the Swiss Transmission System Operator (TSO). 


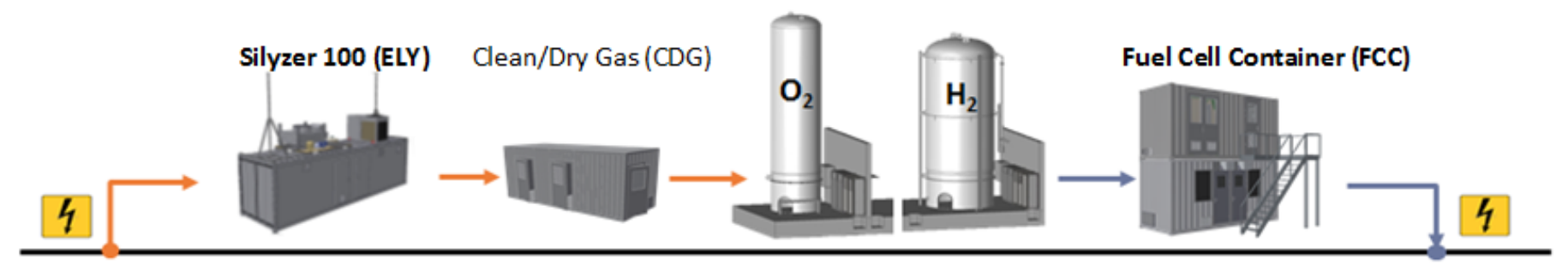

(a) Storing hydrogen produced in the PtG process and re-electrifying it in the GtP process on ESI, while utilizing oxygen, as well.

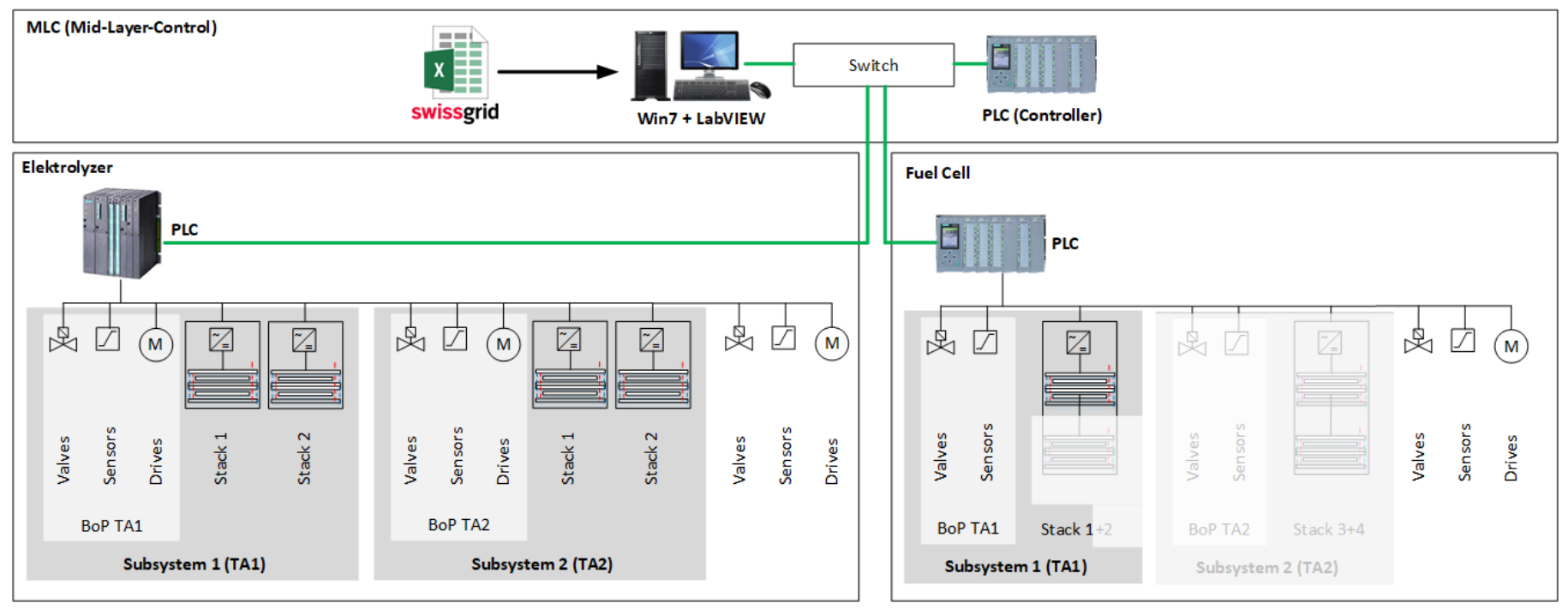

(b) Overview of hierarchical structured controls setup for Power-to-Gas-to-Power (PtGtP) on ESI.

Figure 1: Overview of hydrogen based PtGtP processes on Energy System Integration Platform (ESI).

Although the results are based on the Swiss pre-qualification requirements, they provide an indication that such a PEM based electrolyzer and fuel cell technology would successfully undergo the pre-qualification process for the control reserve markets in other European countries, due to a certain degree of harmonization in the requirements.

The paper is divided into this introduction section, followed by the sections of the test system description for the PtGtP process and by the corresponding control reserve results. The latter in turn is followed by the section of the efficiency considerations made for PtGtP power plants, and ultimately the paper ends with the conclusion's section.

\section{Test system description}

\subsection{Overall system}

The technologies considered for control reserve are part of the Energy System Integration platform, see Fig. 1a. For the PtGtP path, the platform comprises gas tanks for hydrogen and oxygen, connecting the PEM electrolysis and PEM fuel cell systems set-up in 40 feet containers. The semi-commercial electrolyzer and fuel cell demonstrator systems installed on the ESI platform are described in sections 2.4 and 2.5 in more detail.

In addition to the PEM based systems, a gas cleaning facility is present to dry and clean the two gases for safe storage in the tanks. With the electrolyzer able to operate with balanced pressures of hydrogen and oxygen up to 45 bar, gas storage is possible without any mechanical compression after the electrolyzer. In Fig. 1a the position of the clean/dry gas (CDG) unit (supplied by Reicat $\mathrm{GmbH}$, Gelnhausen, Germany) is also depicted.

\subsection{Controls}

The PEM systems are connected via a Mid-Layer-Control (MLC), consisting of a programmable logic controller (PLC) and a personal computer (PC), see Fig. 1b. This controller serves as main controller for the PtGtP path of the ESI platform, but also serves as interconnection point for remote control by higher level controllers, e.g. optimal control [21]. Furthermore, it serves as data acquisition tool and source generator for the load profiles in this study. Due to lack of appropriate frequency measuring equipment, grid frequency was read from past data and then transformed to the corresponding desired power change based on the reserve power capacity.

\subsection{Test overview}

According to the pre-qualification tests by Swissgrid [15] and [16], similar or equal profiles were created and read into the MLC control routines to be sent as power set-points to the electrolyzer and fuel cell containers. The goal of the pre-qualification based tests is to check if the plant power follows the power setpoint over the test durations and whether it stays within the 
boundaries, while providing maximum ramping capability. Generally, power plants have an integrated controller, which reads the grid frequency and reacts to it correspondingly, when operating actively in the primary frequency control regime. In this case, the primary frequency control pre-qualification test from Swissgrid was carried out with a minor change, i.e. the frequency reading was changed in a step-like manner instead of ramping it. The maximum ramping capability then was determined while carrying out the pre-qualification test, without the need for additional testing. For this test, the power requested by the controller must strictly reside inside the limits and must be delivered within a 30 seconds time window. Furthermore, an energy capacity must be held in reserve for a plant with limited energy reservoir (like batteries and hydrogen storage / PEM technologies), such that the maximum contracted bid power $P_{b}$ can be provided over $15 \mathrm{~min}$ at least and $30 \mathrm{~min}$ at most, as proposed by ENTSO-E [22].

For the secondary control reserve case, the plant controller would react to the power requested by the TSO Swissgrid. In this case, the test profile was not altered. Limit violations during the secondary pre-qualification test are not as strictly handled. Specifically, if a violation of the limits in the secondary prequalification test occurs, the time and the magnitude of the violation are recorded and must not, when aggregated over $75 \mathrm{~min}$, exceed a certain limit in order to render the test successful.

\subsection{Electrolyzer}

This is a first generation and therefore semi-commercial electrolyzer (Silyzer 100) from Siemens (Erlangen, Germany), having PEM stack technology from 2011 installed. Hence, to present more representative data, the analysis shown here will be translated into estimates for the electrolyzer performance expected in 2025 and 2040. The Silyzer 100 is built with two subsystems, see Fig. 1b, such that at extended periods of lower part loads one subsystem can be switched off. For the same reason, the electrolyzer system control can switch on/off individual stacks depending on the load required, providing the option to operate the plant as efficient as possible. The electrolyzer can sink according to its specifications DC power in the range of 0 to $200 \mathrm{~kW}$, i.e. four times the $50 \mathrm{~kW}$ maximum power of a single stack.

In order to provide the highest dynamic possible, all pumps must be run, i.e. both subsystems must be turned on, even when only one stack is active. All in all, eleven pumps are integrated, for cooling of the process and for feeding process water to the stacks. Considering this, it becomes evident that in order to prevent inefficient operation, the plant must be operated using smart control routines. Furthermore, the rectifiers installed are laboratory test equipment from Regatron AG (Rorschach, Switzerland) providing a versatile flexibility but they are not optimized for the present application, coming with a relatively low efficiency, i.e. at best $95 \%$. The generated hydrogen and oxygen are kept at balanced pressures and are then fed to the subsequent stage, i.e. the clean/dry gas unit from Reicat, on the way to the storage.

\subsection{Fuel cell}

The fuel cell system resides in a container, which has been engineered, i.e. controls, electrification as well as piping, and has been assembled at PSI. The fuel cell system itself has been developed in cooperation with Swiss Hydrogen SA (Fribourg, Switzerland). The setup for the fuel cell container is similar to the one of the electrolyzer. There are two subsystems, see Fig. $1 \mathrm{~b}$, each with two stacks of $50 \mathrm{~kW}$ nominal power connected in series. As shown in Fig. 1b, the balance of plant can be divided into the one for the entire fuel cell container, including valves, sensors and a pump and into the ones for each subsystem, comprising sensors and valves only. As the development was an ongoing process during the testing period, mainly due to underlying challenges, the system was simplified to one stack only. Nonetheless, the results will hold for the complete setup, as well, since they are presented relative to the nominal power.

Another key difference between the fuel cell and the electrolyzer lies in the number of pumps installed. For the fuel cell container fewer pumps are needed. During the tests one pump was used for the fuel cell system itself and one in an intermediate cooling loop, connecting the container to the exterior cooling infrastructure at PSI. This design results in separated coolant systems, which on the one hand simplifies process control responsibilities, but on the other hand renders a non-optimal solution with respect to efficiency.

Similar, as in the case of the electrolyzer, the power electronic unit is again highly versatile and in consequence it comes with a non optimized efficiency, as well. In contrast to the liquid cooled rectifiers, here the power electronics are air cooled, adding up to the losses of the plant.

\section{Control reserve results}

\subsection{Ramping capability definition and system configurations}

This section presents experimental results from the primary and secondary frequency control tests. The results are presented with respect to the potentially contracted maximum bid power $P_{b}$, which is used in the pre-qualification process as the power to be pre-qualified. In order to make the results more comparable to other technologies $P_{b}$ is used in this paper for the "per unit" (p.u.) definition. Today, Swissgrid computes the normalized ramping rate (hereafter called per unit ramping rate) using the nominal plant power $P_{n}$.

In this work, it is the intention to compare the ramping capability with respect to the domain the plants actually provide power in to stabilize the grid, and therefore the aforementioned first definition will be used (based on $P_{b}$ ). Ultimately, the achievable dynamics can be determined as \% p.u. per second as follows:

$$
\begin{aligned}
& P_{b}:=1 \text { p.u. } \\
& \text { Ramp. capability }:=100 \% \cdot\left(\frac{d P}{d t} / P_{b}\right) \text { in } \frac{\% \text { p.u. }}{\mathrm{s}}
\end{aligned}
$$

In the case of a system capable of providing ancillary services in a symmetric manner over two power quadrants, e.g. ideal battery with supposedly zero auxiliary power, using $P_{n}$ as the base 
p.u. power instead of $P_{b}$ in the definition 1 would be reasonable. However, since the electrolyzer and fuel cell systems operate in one power quadrant only, when running in single mode and since both come with a relatively large auxiliary power components $P_{\min , E L}$ and $P_{\min , F C}$, the selection of $P_{n}$ as the base power for p.u. values leads to a distorted presentation of the ramping capabilities for the two technologies. In contrast, neglecting the auxiliary power and considering the maximum contracted bid power $P_{b}$ as the base p.u. power is assumed to result in a more comparable form of the ramping capability for ancillary services. The formal derivation for the maximum bid power to be offered $P_{b}$ is given in equation 3

The symbol $P_{W A, 0}$ is introduced for the power a power system drives when the grid frequency is $50 \mathrm{~Hz}$, and when the power system is activated for frequency control. Therefore, the power system must be able to provide the minimum contracted power
$P_{W A, 0}-P_{b}$, i.e. the power when the full reserve capacity is activated in the negative direction, and the maximum contracted power $P_{W A, 0}+P_{b}$, i.e. the power when the full reserve capacity is activated in the positive direction.

$$
\begin{aligned}
P_{b} & =P_{n}-P_{W A, 0} \\
P_{W A, 0} & =\left\{\begin{array}{l}
\left(P_{n}-P_{\text {min }}\right) / 2+P_{\text {min }} \\
0, \text { if } P_{\text {min }}<-P_{n}
\end{array}\right.
\end{aligned}
$$

In the rest of this section, first the responses to the primary frequency control test for the electrolyzer and fuel cell systems are shown. Thereafter, the responses to the secondary control reserve test are discussed. As mentioned previously, all tests are performed in a symmetric manner and separately for the electrolyzer and fuel cell; in other words, no experimental testing with the overall PtGtP configuration is reported in this paper.

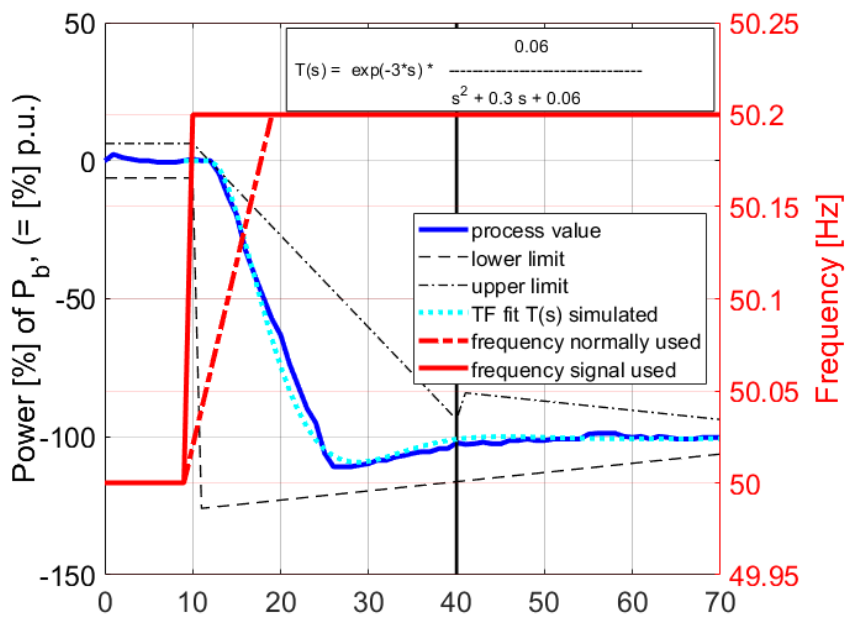

(a) Electrolyzer Frequency Increase Response.

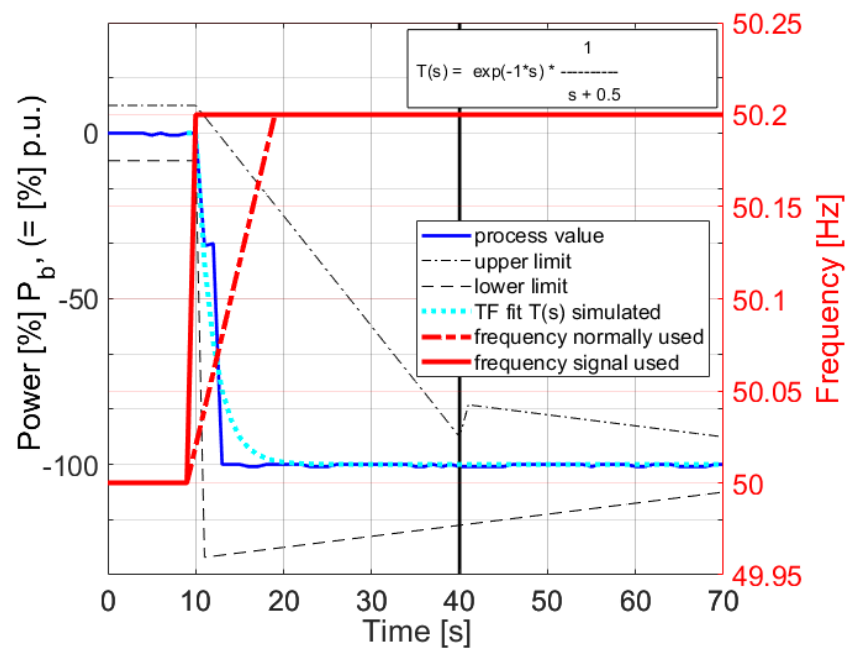

(c) Fuel Cell Frequency Increase Response.

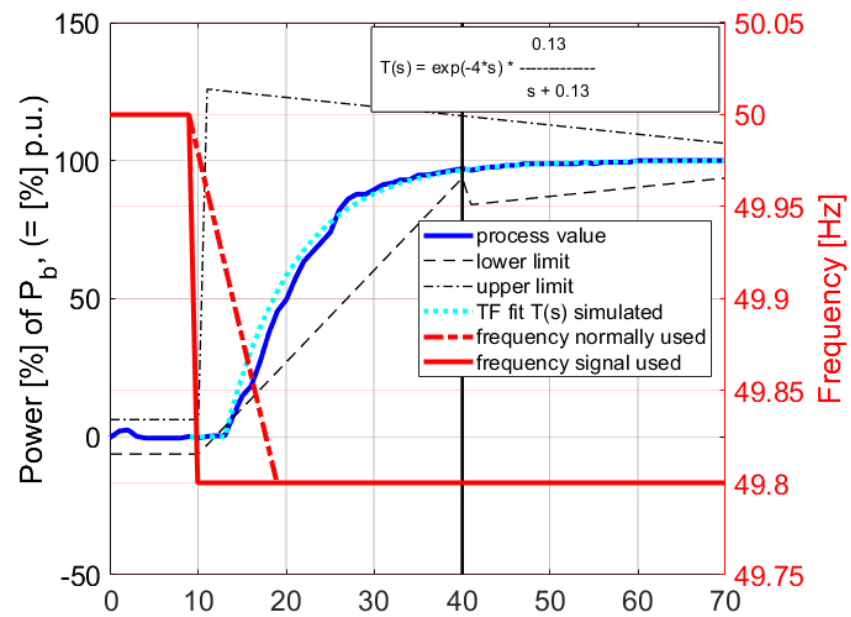

(b) Electrolyzer Frequency Decrease Response.

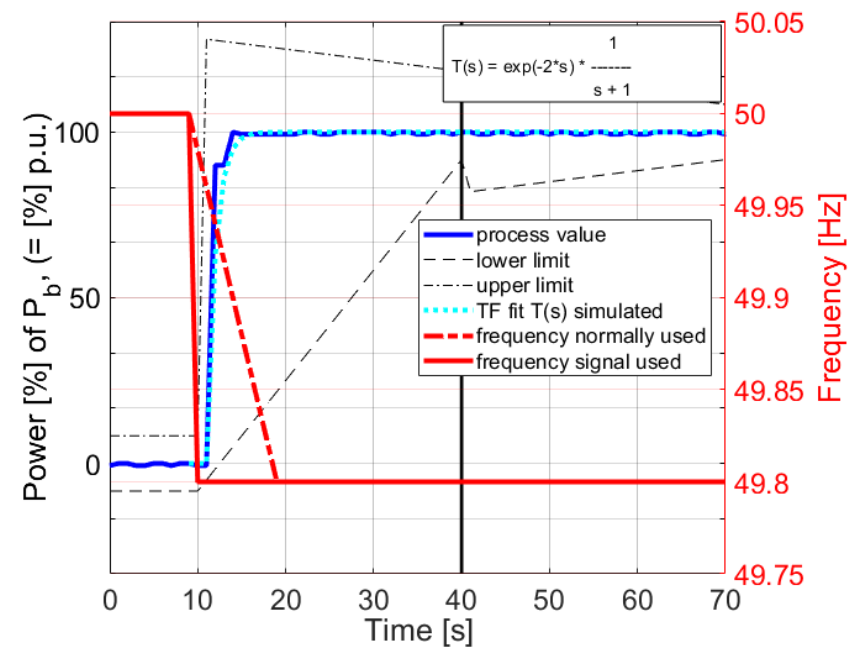

(d) Fuel Cell Frequency Decrease Response.

Figure 2: Sub-MW PEM technologies in pre-qualification-like tests for primary control reserve. Normally, the grid frequency would be ramped during the test. Here, however, a step function in the power setpoint was applied as indicated with the curve "frequency signal used" in order to determine the maximum ramping capabilities during the pre-qualification process. In addition, the transfer functions $T(s)$ have been verified in simulation. The units were controlled to achieve the best ramping capability (controller values were not recorded). Because of the feed-forward control in the fuel cell's case, its transfer function reads: $G(s)=T(s) \cdot 0.96$. 


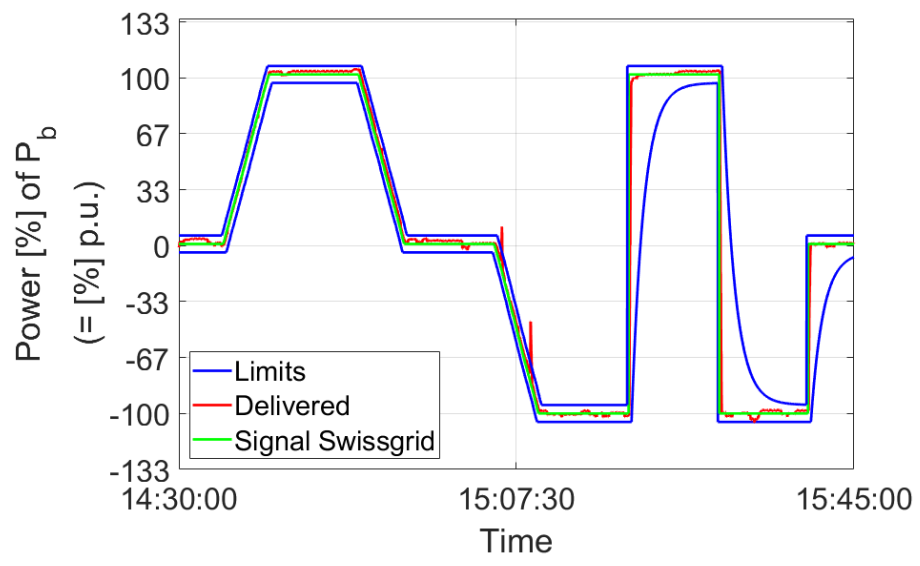

(a) Electrolyzer response (positive reserve power values indicate a reduction in the consumed power).

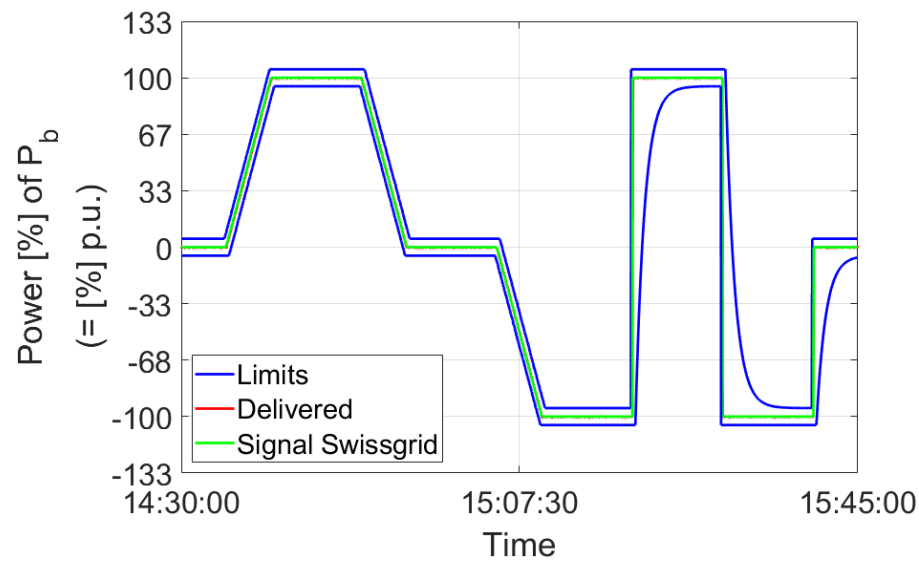

(b) Fuel cell response (positive reserve power values indicate an increase in the generated power).

Figure 3: Sub-MW PEM technologies in pre-qualification for secondary control reserve; testing positive and negative control reserve (i.e. symmetric reserve, including both positive and negative control).

\subsection{Primary reserve}

\subsubsection{Electrolyzer}

The electrolyzer balances increasing frequency in the electric grid by sinking power from the grid, producing hydrogen and oxygen. The higher the grid frequency, the more power must be sunk. In case of a frequency decrease in the grid, the electrolyzer reduces the power to be sunk correspondingly. The two processes are illustrated in Fig. $2 \mathrm{a}$ and $2 \mathrm{~b}$, where the frequency change is shown in red and the electrolyzer power in blue. The power $P_{W A, 0}$ is $60 \mathrm{~kW}$ in this case and the maximum contracted bid power $P_{b}$ is $40 \mathrm{~kW}$ (whereas $P_{n}$ is $100 \mathrm{~kW}$ ).

The electrolysis plant responds within the required $30 \mathrm{sec}-$ onds time window and does not violate the upper or lower limits of the tolerance band of this altered primary control reserve pre-qualification test. The relatively slow response time after the start of the frequency change is due to the non-optimized communication schemes of the Silyzer 100 PLC with the higherlevel controls. As discussed above, in a real world scenario, the communication to the MLC would not be needed, since an integrated controller in the system would observe the grid frequency and react upon changes correspondingly, in a more responsive manner.

The ramping capability is limited when pressurized oxygen is used in the subsequent processes. The plant must then be operated with balanced pressures of hydrogen and oxygen, which reduces the possibility to respond with higher dynamics. The relative achievable dynamics are about $\pm 8 \%$ p.u. per second for the semi-commercial Silyzer 100 electrolyzer.

\subsubsection{Fuel cell system}

In the case of the fuel cell, an immediate response on frequency changes is observed, and the response stays within the limits and settles within few seconds, see Fig. 2c and 2d. Here the operating power for an electric grid frequency of $50 \mathrm{~Hz}$ $\left(P_{W A, 0}\right)$ is $30 \mathrm{~kW}$, and the contracted maximum bid power $P_{b}$ is $15 \mathrm{~kW}$ ( $P_{n}$ was $45 \mathrm{~kW}$ due to stability issues at that time).
In the case of the fuel cell system, a frequency increase is simulated by requesting a reduction in power from the fuel cell via the MLC to reduce the electric output. Analogously, for a lower grid frequency, the MLC requests more power to be injected into the electric grid by the fuel cell system. A ramping capability of around $\pm 33 \%$ p.u. per second is identified for the fuel cell.

\subsection{Secondary reserve}

The secondary control reserve pre-qualification test cycle has a duration of $75 \mathrm{~min}$, where the investigated electrolyzer and fuel cell systems must follow the requested progression line, as shown and explained in section 2.3. The results of the prequalification tests in this case are given in Fig. $3 \mathrm{a}$ and $3 \mathrm{~b}$ showing the behavior of the Silyzer 100 and fuel cell system, respectively. In both cases the tests were completed successfully, full-filling all test criteria, such as: staying within the limits for the most part of the test duration and achieving the desired dynamics. In addition, the requested power setpoint could be tracked in both cases almost perfectly. The small violations of the admissible region in the case of the Silyzer 100 was mainly due to the non optimized MLC controller.

The controller was not able to counteract the stack management routine of the low level PLC controller of the Silyzer 100, mainly due to the communication delay caused by the electrolyzer. The stack management routine determines at what load point which stacks need to be active and which ones are switched off.

\section{Efficiency considerations}

Efficiency of the Power-to-Power cycle is a key property for the application in frequency control because efficiency is directly linked to the cost. It is derived in a first step using the hardware on the ESI platform with a designed power in the order of $100 \mathrm{~kW}$, representing large scale research installations, but not yet installations of industrial scale. Additionally, we 
put the obtained round-trip efficiency with the plant size investigated into perspective to the expected round-trip efficiencies for industrial installations in the near future (2025) and in 2040. Throughout the calculations made, the lower heating value of hydrogen (LHV) has been used. Fig. 4 presents the efficiency analysis for electron-to-electron storage, i.e. AC-to-AC power, where the values in the top graph are derived from the ESI platform. As the efficiency depends on the operating point, the potentially best operating points possible have been selected. Hence, the data presented is based on the nominal load for the electrolyzer, i.e. $100 \mathrm{~kW}$ of DC power and at part load for the fuel cell, i.e. $60 \%$ of $P_{n}$. Since the fuel cell container operated just one system with nominal power $P_{n}$ of $50 \mathrm{~kW}, 60 \%$ of $P_{n}$ becomes $30 \mathrm{~kW}$ of DC power. From these experimental data a round-trip efficiency for the installations on ESI of $24.5 \%$ is computed, as shown in Fig. 4 a

Table 1

Loss categories considered during analysis. Measured data from ESI platform are used for today's scenario; extrapolated data are used for the 2025 and 2040 scenarios.

\begin{tabular}{|l|l|l|}
\hline Category & Explanation & Determination \\
\hline BoP & $\begin{array}{l}\text { Balance of plant } \\
\text { consumption }\end{array}$ & measured \\
\hline $\begin{array}{l}\text { Conver- } \\
\text { ter }\end{array}$ & $\begin{array}{l}\text { Power electronics } \\
\text { losses }\end{array}$ & measured \\
\hline EC & $\begin{array}{l}\text { Electrochemical } \\
\text { losses }\end{array}$ & $\begin{array}{l}\text { based on average cell } \\
\text { voltage measurement } \\
\text { and the thermoneutral } \\
\text { voltage (LHV based) }\end{array}$ \\
\hline GC & $\begin{array}{l}\text { Gas-crossover losses, } \\
\text { electrolyzer only }\end{array}$ & $\begin{array}{l}\text { based on } \\
\text { work in [24] }\end{array}$ \\
\hline GUL & $\begin{array}{l}\text { Gas utilization losses, } \\
\text { fuel cell system only }\end{array}$ & $\begin{array}{l}\text { based on EC and } \\
\text { measurements }\end{array}$ \\
\hline
\end{tabular}

Different aspects, which are discussed in more detail in section 4.0.1 play an important role when assessing these figures:

- The balance of the plant is not as well optimized for the systems at hand, as it would be the case for systems in the MW range.

- The electrolyzer is quite old (2011), and advances have been made in the fields of electrochemical performance and plant design, resulting in a higher efficiency.

- The power electronic units employed are not optimized for this application, and more efficient units can be found in the MW domain.

Furthermore, the data shown in Fig. 4 is given with respect to standard temperature and pressure (STP) conditions for simplicity reasons. In other words, no corrections were made by considering the deviations in the operating contidition from STP conditions. The operating conditions were approximately $60{ }^{\circ} \mathrm{C}$ operating temperature for both systems and operating pressure
25 bar gauge for the Silyzer 100 and approximately 2.5 bar gauge for the fuel cell. Fig. 4 shows, that the electrolyzer efficiency is given with respect to $\mathrm{AC}$ power fed and the produced hydrogen at the outlet of the plant is given with respect to the lower heating value of hydrogen.

The loss categories for the Power-to-Gas (PtG) and Gas-toPower (GtP) processes considered are shown in Table 11. Their cumulative relative effect is shown in Fig. 4 Their single relative effect is given in Tables 3 and 4 . The estimated future efficiencies are presented in Fig. $4 b$ and $4 c .39 \%$ round-trip efficiency in 2025 and $48 \%$ in 2040. The data is based on laboratory measurements and systems commercially available today, and then extrapolated for 2025 based on Table 3, as well as for 2040, using the values in Table 4. The latter table is based on the one for 2025 , additionally with rough estimates of improvements possible over a time period of 15 years. These estimates, however, are considered to be relatively conservative, when observing the improvements made over the last two decades. A detailed explanation for derivation of the values for 2025 and 2040 is given in section 4.0.1 below.

\subsubsection{Losses on ESI platform today and estimated future losses}

Tables 3 and 4 contain the measured and estimated future individual efficiency losses for the PEM electrolyzer and the fuel cell technologies. The 2011 and 2017 technology values are measured with the ESI installations while operating at the mentioned load points over a substantial amount of time, after which the plants were assumed to be in steady state. The formal calculations made to determine the losses that were not directly measured are listed here:

$$
\begin{aligned}
\mathrm{EC}_{\mathrm{EL}} & =\left(1-\frac{E_{\mathrm{LHV}}^{0}}{u_{\mathrm{c}, \mathrm{avg}, \mathrm{EL}}}\right) \cdot p_{\mathrm{DC}, \mathrm{EL}} \\
\mathrm{EC}_{\mathrm{FC}} & =\left(1-\frac{\mathrm{u}_{\mathrm{c}, \mathrm{avg}, \mathrm{FC}}}{E_{\mathrm{LHV}}^{0}}\right) \cdot \underbrace{\left(p_{\mathrm{DC}, \mathrm{FC}}+\mathrm{EC}_{\mathrm{FC}}\right)}_{\text {Power equ. gas fed to stack }} \\
\mathrm{BoP} & =p_{\mathrm{AC}, \mathrm{EL}}-p_{\mathrm{DC}, \mathrm{EL}}-\text { Converter } \\
\mathrm{GC} & =j_{x} \cdot A \cdot n_{\mathrm{st}} \cdot n_{\mathrm{c}} \cdot \frac{M \cdot c_{2}}{2 \cdot F \cdot \rho} \cdot c_{1} \cdot W_{\mathrm{LHV}} \\
\mathrm{GUL} & =\dot{m} \cdot c_{1} \cdot W_{\mathrm{LHV}}-p_{\mathrm{DC}, \mathrm{FC}}-\mathrm{EC}_{\mathrm{FC}} \\
\text { with } c_{1} & =\frac{60 \mathrm{~min} / \mathrm{h}}{1000 \mathrm{nl} / \mathrm{Nm}^{3}} \text { and } c_{2}=60 \mathrm{~s} / \mathrm{min} .
\end{aligned}
$$

For both systems the electrochemical losses $\mathrm{EC}_{\mathrm{EL}}$ and $\mathrm{EC}_{\mathrm{FC}}$ were derived using the average electric cell efficiency. The latter depends on the average cell voltage and the thermoneutral voltage. The average cell voltages $u_{\mathrm{c}, \mathrm{avg}, \mathrm{EL}}$ and $u_{\mathrm{c} \text {,avg,FC }}$ were determined at nominal load $p_{\mathrm{DC}, \mathrm{EL}}$ of $100 \mathrm{~kW}$ for the electrolyzer and at part load $p_{\mathrm{DC}, \mathrm{FC}}$ of $30 \mathrm{~kW}$ for the fuel cell. The average cell voltage itself stems from the measured stack terminal voltage divided by the number of cells stacked together. This figure is then put into relation to the thermoneutral voltage $E_{\mathrm{LHV}}^{0}=1.253 \mathrm{~V}$ 
[23], to receive the average electric cell efficiencies. Using the electric cell efficiencies in equations 5 and 6 correspondingly, in combination with the DC power measurement, the electrochemical losses then can be calculated directly in the case of the electrolyzer and indirectly in the fuel cell's case.

Table 2

Parameters used for efficiency calculations

(* Hydrogen, ** Silyzer 100)

\begin{tabular}{|c|l|l|}
\hline Param. & Value & Remark \\
\hline$E_{\mathrm{LHV}}^{0}$ & $1.253 \mathrm{~V}$ & Thermoneutral voltage* \\
$W_{\mathrm{LHV}}$ & $3 \mathrm{kWh} / \mathrm{Nm}^{3}$ & Volume specific energy* \\
$A_{\mathrm{EL}}$ & $300 \mathrm{~cm}^{2}$ & Active cell area** \\
$p_{\mathrm{EL}}$ & $25 \mathrm{barg}$ & Operated pressure** \\
$p_{\mathrm{FC}}$ & $2.5 \mathrm{barg}$ & Operated pressure FC \\
$n_{\mathrm{c}}$ & 40 cells & Cells per stack** \\
$n_{\mathrm{st}}$ & 4 stacks & Number of stacks** \\
$M$ & $2.01588 \mathrm{~g} \mathrm{~mol}^{-1}$ & Molar weight* \\
$F$ & $96485.33 \mathrm{~A} \mathrm{sec}^{*} / \mathrm{mol}$ & Faraday's constant \\
$\rho$ & $0.0899 \mathrm{~kg} \mathrm{Nm}^{-3}$ & Density* \\
\hline
\end{tabular}

For the Silyzer 100 the balance of plant losses are calculated as the difference of the supplied power minus the DC power and minus the converter losses, of which all entities were measured, as shown in equation 7. The fuel cell system's balance of plant power consumption was measured directly.

In order to determine the gas crossover losses in equation 8 , the relationship of the crossover current in dependence of pressure and temperature as documented in [24] was used. Roughly $10 \mathrm{~mA} / \mathrm{cm}^{2}$ of current density $j_{x}$ is lost due to gas crossover at an operating pressure of $p_{\mathrm{EL}}=25 \mathrm{bar}$ and temperature of $65^{\circ} \mathrm{C}$. Filling in the data for the active cell area of $A=300 \mathrm{~cm}^{2}$, the number of cells per stack $n_{\mathrm{c}}=40$ and the number of stacks $n_{\mathrm{st}}=4$, and using the conversion factor of the volume specific chemical energy content of hydrogen at standard temperature and pressure with the value of $W_{\mathrm{LHV}}=3.0 \mathrm{kWh} / \mathrm{Nm}^{3}$ with respect to the lower heating value, almost all data to determine the gas crossover losses $\mathrm{GC}$ are available. The remaining factors to be filled in are the molar mass $M=2.01588 \mathrm{~g} \mathrm{~mol}^{-1}$ of hydrogen, the Faraday's constant $F=96485.33 \mathrm{~A} \mathrm{sec} / \mathrm{mol}$ and the hydrogen's density $\rho=0.0899 \mathrm{~kg} \mathrm{Nm}^{-3}$.

For the fuel cell system the losses induced by an imperfect gas utilization are determined by subtracting the EC losses and the DC power generated from the hydrogen power equivalent of the hydrogen massflowmeter reading, as shown in equation 9 The power equivalent of the massflow reading $\dot{m}$ is calculated using the volume specific chemical energy of hydrogen $W_{\mathrm{LHV}}=$ $3 \mathrm{kWh} / \mathrm{Nm}^{3}$ at standard temperature and pressure with respect to the lower heating value.

As the load operated by the electrolyzer shifts from below nominal load towards nominal load, the relation between losses, e.g., the balance of plant and the power consumed from the grid becomes smaller and the system efficiency increases. Therefore, the preferred control scheme is to operate the plant around nominal power in order to perform most efficiently. The same holds
Table 3

Relative losses in detail of PtG and GtP processes. Comparing ESI data and expected values potential in 2025; loss categories defined in Table 1 Data is rounded to first decimal place. $\Delta>0$ means fewer losses.

\begin{tabular}{c|c|c|c|c|c|c} 
& \multicolumn{5}{|c}{ Losses in \% of system feed entity: } \\
& \multicolumn{3}{|c|}{ PtG } & \multicolumn{4}{c}{ GtP } \\
\hline Category & 2011 & 2025 & $\Delta$ & 2017 & 2025 & $\Delta$ \\
\hline BoP & 5.8 & 5 & 0.8 & 5.6 & 1.5 & 4.2 \\
Converter & 8.0 & 0.5 & 7.5 & 4.0 & 1.6 & 2.3 \\
EC & 38.5 & 29.7 & 8.8 & 33.5 & 34.5 & -1.1 \\
GC & 0.5 & 0.7 & -0.2 & - & - & - \\
GUL & - & - & - & 3.6 & 0.5 & 3.1 \\
\hline Tot. EL & 52.9 & 35.9 & 17.0 & - & - & - \\
CDG & 1.2 & 1.2 & 0 & - & - & - \\
\hline Total & 54.1 & 37.1 & 17.0 & 46.7 & 38.1 & 8.5 \\
\hline (Compres.) & 3.0 & 3.0 & 0 & - & - & -
\end{tabular}

Table 4

Relative losses in detail of PtG and GtP processes. Comparing ESI data versus potential in 2040; loss categories defined in Table 1 Data is rounded to first decimal place. $\Delta>0$ means fewer losses.

\begin{tabular}{c|c|c|c|c|c|c} 
& \multicolumn{5}{|c}{ Losses in \% of system feed entity: } \\
& \multicolumn{3}{|c}{ PtG } & \multicolumn{3}{c}{ GtP } \\
\hline Category & 2011 & 2040 & $\Delta$ & 2017 & 2040 & $\Delta$ \\
\hline BoP & 5.8 & 3 & 2.8 & 5.6 & 1.2 & 4.4 \\
Converter & 8.0 & 0.5 & 7.5 & 4.0 & 1.4 & 2.5 \\
EC & 38.5 & 26.8 & 11.7 & 33.5 & 27.2 & 6.3 \\
GC & 0.5 & 0.5 & 0 & - & - & - \\
GUL & - & - & - & 3.6 & 0.24 & 3.4 \\
\hline Tot. EL & 52.9 & 30.8 & 22.1 & - & - & - \\
CDG & 1.2 & 0.6 & 0.6 & - & - & - \\
\hline Total & 54.1 & 31.4 & 22.7 & 46.7 & 30.1 & 16.6 \\
\hline (Compres.) & 3.0 & 3.0 & 0 & - & - & -
\end{tabular}

true for the fuel cell. Future controls of the plants at hand have to incorporate efficiency models, such that the plants will be operated in the most efficient way.

In addition to the electrolyzer and fuel cell losses, the efficiency analysis also considers losses in the clean/dry gas unit due to power consumption, and other losses like reactor losses and losses in the pressure swing adsorption process when drying the gases. They are summed up in Tables 3 and 4 , and represented by a single figure only, since the focus is on the PEM based technologies.

For the sake of completeness, the derivation of the 2025 and 2040 estimates is given below:

- Laboratory measurements were used for the electrochemical losses of the electrolyzer [25], indicating a potential improvement in electrolyzer system efficiency of around $8.8 \%$ points,

- Information from datasheets was considered, like the one from the power converters from the ABB ESM (energy storage) and ABB Enviline (traction) product lines [26]. 


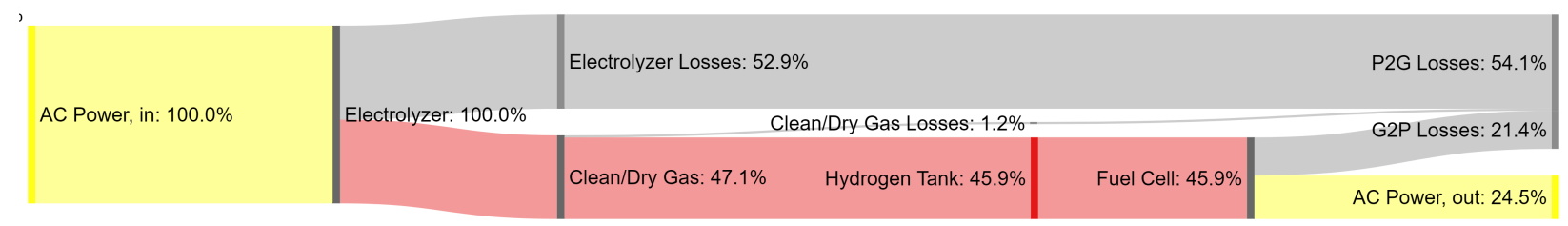

(a) PtG performance state 2011 and fuel cell performance (GtP) state 2017 on ESI platform.

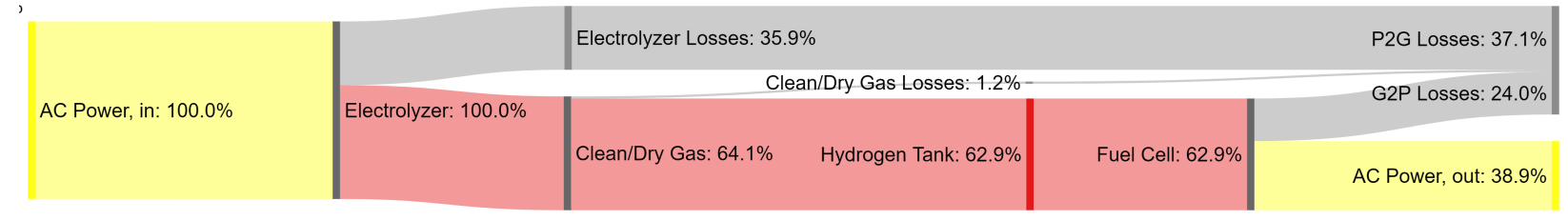

(b) PtGtP efficiency performance estimated for 2025.

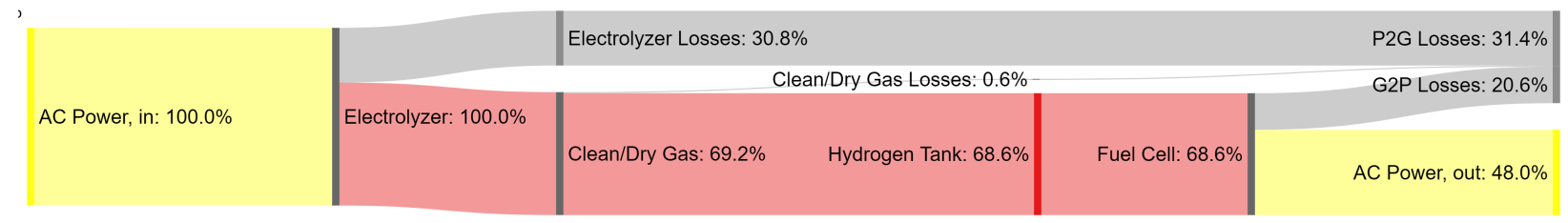

(c) PtGtP efficiency performance estimated for 2040.

Figure 4: Efficiency development for PEM PtGtP technologies.

The latter reports for the rectifier an efficiency of $99.5 \%$. The ESM line lists an overall efficiency of $97 \%$.

- From efficiency maps of the Silyzer 200 [27], the BoP losses of $5 \%$ at nominal power were estimated. Since the latest version Silyzer 300 uses fewer pumps compared to the Silyzer 200, this number may be even smaller.

- The main auxiliary part for the fuel cell container is the cooling pump which is used for the cooling of all the systems. It is operating at a constant power. This leads to following inverse relationship: when increasing the system power by a factor of 4 , the BoP losses will decrease to a fourth of the current value.

- The gas utilization losses for the fuel cell possibly drop under $1.0 \%$ [14].

Since no compression stage is integrated in the ESI platform, the corresponding losses are not incorporated into the Sankey diagrams. This is valid for applications where the electrolyzer can pressurize the gas to the maximum storage pressure level, which is 45 bar. Nonetheless, for the sake of completeness, the compression losses are stated in the Tables 3 and 4 . Based on the ionic compressor 50 datasheet from Linde [28] (Dublin, Ireland), the compression would add an extra three percent of losses with respect to the power fed to the electrolyzer in the present case.

\section{Conclusion}

Polymer electrolyte membrane based technologies in Powerto-Gas and Gas-to-Power applications cannot only store excess renewable energy in the form of hydrogen and re-electrify it as needed, e.g. for peak shaving, but in this work they have been identified as suitable resources for provision of frequency reserves in the electricity grid. Specifically, we have shown that such technologies could, in principle, successfully pass the prequalification tests for primary and secondary frequency control, which are typically required by transmission system operators for participation in the ancillary services market.

The ramping dynamics of polymer electrolyte membrane based technologies found in this work are approximately $8 \%$ p.u. per second for the semi-commercial Silyzer 100 electrolyzer and approximately $33 \%$ p.u. per second for the fuel cell, which is a development project of Paul Scherrer Institute and Swiss Hydrogen SA. Therefore, the balanced-pressure electrolyzer comes with a slightly lower ramping capability than pumped-storage hydropower, which is characterized by a ramping rate of $10 \%$ p.u. per second [19]. The ramping rate of the fuel cell on the system level considered is to the best of our knowledge much faster than that of pumped-storage hydropower and faster than that of existing fuel cell technologies, as well. However, much slower than the ramping rate in the order of $200 \%$ p.u. per second achievable with batteries [18].

The efficiencies determined in this work are approximately $63 \%$ for Power-to-Gas and $62 \%$ for Gas-to-Power, leading to a round-trip efficiency of $39 \%$ in 2025 . Comparing the Gas-to-Power efficiency of $62 \%$ in 2025 to an existing MW re-electrification solution with around $50 \%$, as shown in the introduction, the difference of around $12 \%$ in the re-electrification efficiency translates overall to a gain of $7.5 \%$ in the round-trip efficiency. This is mainly because of using pure oxygen instead of air, which reduces losses in the Gas-to-Power process.

In fact, polymer electrolyte membrane based technologies are not only viable solutions to stabilize the electric grid but come with a key advantage when compared to batteries. Precisely, adding energy capacity to an existing Power-to-Gas-to-Power 
power plant is economically more attractive than for batteries.

In the future, it will be interesting to assess what the optimal system design looks like, when considering economic aspects next to the reported dynamics and efficiencies in this work. Finally, it would be interesting to perform experimental pre-qualification tests for primary and secondary frequency control with the overall Power-to-Gas-to-Power system, i.e. with the electrolyzer and fuel cell at the same time.

\section{Declaration of competing interest}

The authors declare that they have no known competing financial interests or personal relationships that could have appeared to influence the work reported in this paper.

\section{Acknowledgements}

This work was funded as part of the project Integration of Storage Technologies for Stabilization of the Power Grid in cooperation with Swissgrid AG, Aarau, Switzerland. Additional financial support is graciously acknowledged from the ETH domain (Switzerland) via the funds for "Coordinated Research".

\section{References}

[1] EUROPEAN COMMISSION, "A Clean Planet for all - A European strategic long-term vision for a prosperous, modern, competitive and climate neutral economy", Brussels, November 2018, pp. 3-10.

[2] B. Kroposki, B. Johnson, Y. Zhang, V. Gevorgian, P. Denholm, B. Hodge et al., "Achieving a $100 \%$ Renewable Grid: Operating Electric Power Systems with Extremely High Levels of Variable Renewable Energy", in IEEE Power and Energy Magazine, vol. 15, no. 2, pp. 61-73, March-April 2017.

[3] IRENA, "Innovation landscape brief: Innovative ancillary services", International Renewable Energy Agency, Abu Dhabi, 2019.

[4] M. Koller, T. Borsche, A. Ulbig, and G. Andersson, "Review of grid applications with the Zurich 1MW battery energy storage system", Electric Power Systems Research, Volume 120, 2015, Pages 128-135, ISSN 03787796.

[5] A. Buttler and H. Spliethoff, "Current status of water electrolysis for energy storage, grid balancing and sector coupling via Power-to-Gas and power-to-liquids: A review“, Renewable and Sustainable Energy Reviews, Volume 82, Part 3, 2018, Pages 2440-2454, ISSN 1364-0321.

[6] Deutsche Energie-Agentur GmbH, "Windgas Haßfurt - Frequenzstabilisierung im Stromnetz (Primärregelenergie)", visited November 2021, 2016.

[7] M.H. Marzebali, M. Mazidi, and M. Mohiti, "An adaptive droop-based control strategy for fuel cell-battery hybrid energy storage system to support primary frequency in stand-alone microgrids", Journal of Energy Storage, Volume 27, 2020, 101127, ISSN 2352-152X.

[8] Z. Ma, J. Eichman, and J. Kurtz, "Fuel Cell Backup Power System for Grid Service and Microgrid in Telecommunication Applications." ASME. J. Energy Resour. Technol. June 2019; 141(6): 062002.

[9] F. Alshehri, V.G. Suarez, J.L. Torres, A. Perilla, and M.A. van der Meijden, "Modelling and evaluation of PEM hydrogen technologies for frequency ancillary services in future multi-energy sustainable power systems", Heliyon 5 (2019) e01396.

[10] M. Koller, V.M. Gonzalez, A. Chacko, T. Borsche, and A. Ulbig, "Primary control reserves provision with battery energy storage systems in the largest European ancillary services cooperation”, Conference: Cigré, Paris, 2016.

[11] D. Parra, L. Valverde, F.J. Pino, and M.K. Patel, "A review on the role, cost and value of hydrogen energy systems for deep decarbonisation", Renewable and Sustainable Energy Reviews, Volume 101, 2019, Pages 279-294, ISSN 1364-0321.
[12] B. Marchi, M. Pasetti, and S. Zanoni, "Life Cycle Cost Analysis for BESS Optimal Sizing”, Energy Procedia, Volume 113, 2017, Pages 127-134, ISSN 1876-6102

[13] Paul Scherrer Institut, "Energy System Integration Platform”, PSI, Villigen, 2020.

[14] F.N. Büchi, M. Hofer, C. Peter, U. Cabalzar, J. Bernard, U. Hannesen et al. "Towards re-electrification of hydrogen obtained from the Power-to-Gas process by highly efficient $\mathrm{H} 2 / \mathrm{O} 2$ polymer electrolyte fuel cells" in RSC Advances, Issue 99, Pages 56139-56146, 2014.

[15] M. Scherer, D. Schlipf, W. Sattinger, and S. Margelou, "Test zur Primärregelfähigkeit", Swissgrid AG, Version 2, 2020.

[16] Swissgrid AG, "Test for secondary control capability", Version 3.0, 2020.

[17] N.K. Noyanbayev, A.J. Forsyth, and T. Feehally, "Efficiency analysis for a grid-connected battery energy storage system", Materials Today: Proceedings, Volume 5, Issue 11, Part 1, 2018, Pages 22811-22818, ISSN 2214-7853

[18] T. Feehally, A.J. Forsyth, R. Todd, M.P. Foster, D. Gladwin, D.A. Stone et al., "Battery energy storage systems for the electricity grid: UK research facilities", 8th IET International Conference on Power Electronics, Machines and Drives (PEMD 2016), 2016, pp. 1-6

[19] O.B. Tör, U. Karaagac, and E. Benlier, "Step-Response Tests of a Unit at Atatürk Hydro Power Plant and Investigation of the Simple Representation of Unit Control System.” IEEE PES, 36th North American Power Symposium. 2005.

[20] Hydrogenics, "Fuel Cell Megawatt Power Generation Platform", Hydrogenics, Canada, 2020.

[21] B. Flamm, C. Peter, F.N. Büchi, and J. Lygeros, "Electrolyzer modeling and real-time control for optimized production of hydrogen gas", Applied Energy, Volume 281, 2021, 116031, ISSN 0306-2619.

[22] entsoe, "All Continental European and Nordic TSOs' proposal for a Cost Benefit Analysis methodology in accordance with Article 156(11) of the Commission Regulation (EU) 2017/1485 of 2 August 2017 establishing a guideline on electricity transmission system operation", European NEtwork of Transmission Sysgem Operators for Electricity, Belgium, 2018.

[23] A. Lamm, W. Vielstich, and H. A. Gasteiger. "Handbook of Fuel Cells Vol. 1'. John Wiley \& Sons Ltd, 1 edition, 2003.

[24] M. Suermann, T. Kiupel, T.J. Schmidt, and F.N. Büchi, "Electrochemical Hydrogen Compression: Efficient Pressurization Concept Derived from an Energetic Evaluation", Journal of The Electrochemical Society. 2017;164:F1187-F95.

[25] T. Schuler, J.M. Ciccone, B. Krentscher, F. Marone, C. Peter, T.J. Schmidt et al., "Hierarchically Structured Porous Transport Layers for Polymer Electrolyte Water Electrolysis", Advanced Energy Materials. 2019:1903216.

[26] ABB, "Energy Storage Modules (ESM)", ABB, Switzerland, 2020.

[27] M. Kopp, D. Coleman, C. Stiller, K. Scheffer, J. Aichinger, and B. Scheppat, "Energiepark Mainz: Technical and economic analysis of the worldwide largest Power-to-Gas plant with PEM electrolysis", International Journal of Hydrogen Energy, Volume 42, Issue 19, 2017, Pages 1331113320, ISSN 0360-3199.

[28] Linde AG, Gases Division. "Hydrogen technologies. The ionic compressor 50". Linde AG, Pullach, Germany, 2016.

[29] H. Kim, C.Y. Cho, J.H. Nam, D. Shin, and T. Chung, "A simple dynamic model for polymer electrolyte membrane fuel cell (PEMFC) power modules: Parameter estimation and model prediction", International Journal of Hydrogen Energy, Volume 35, Issue 8, 2010, Pages 3656-3663, ISSN 0360-3199

[30] A. Saadi, M. Becherif, A. Aboubou, and M.Y. Ayad, "Comparison of proton exchange membrane fuel cell static models", Renewable Energy, Volume 56, 2013, Pages 64-71, ISSN 0960-1481

[31] T.C. Roberts and P.J. Cunningham, "Fuel Cell Frequency Response Function Modeling for Control Applications." Proceedings of the ASME 2010 8th International Conference on Fuel Cell Science, Engineering and Technology. ASME 2010 8th International Fuel Cell Science, Engineering and Technology Conference: Volume 1. Brooklyn, New York, USA. June 14-16, 2010. pp. 619-625. ASME.

[32] A.J. del Real, A. Arce, and C. Bordons, "Development and experimental validation of a PEM fuel cell dynamic model", Journal of Power Sources, Volume 173, Issue 1, 2007, Pages 310-324, ISSN 0378-7753

[33] P. Corbo, F. Migliardini, and O. Veneri, "Experimental analysis and management issues of a hydrogen fuel cell system for stationary and mobile 
application", Energy Conversion and Management, Volume 48, Issue 8, 2007, Pages 2365-2374, ISSN 0196-8904

[34] J.M. Lee and B.H. Cho, "A Dynamic Model of a PEM Fuel Cell System", 2009 Twenty-Fourth Annual IEEE Applied Power Electronics Conference and Exposition, 2009, pp. 720-724

[35] P. Olivier, C. Bourasseau, and P.B. Bouamama, "Low-temperature electrolysis system modelling: A review", Renewable and Sustainable Energy Reviews, Volume 78, 2017, Pages 280-300, ISSN 1364-0321

[36] R. Mandal and K. Chatterjee, "Frequency control and sensitivity analysis of an isolated microgrid incorporating fuel cell and diverse distributed energy sources", International Journal of Hydrogen Energy, Volume 45, Issue 23, 2020, Pages 13009-13024, ISSN 0360-3199 